\title{
El dilema de la ética del revisor fiscal que actúa bajo contrato laboral: El caso colombiano*
}

The dilemma of the ethics of tax reviewer acting under a labor contract: The Colombian Case O dilema da ética do auditor tributário atuando sob contrato de trabalho: O caso colombiano

\author{
Martha Olaya \\ Universidad de la Costa, Colombia \\ ORCID: https://orcid.org/0000-0001-9436-6203 \\ Olson Ortíz \\ Universidad de la Costa, Colombia \\ oortiz7@cuc.edu.co \\ ORCID: https://orcid.org/0000-0001-6032-8655
}

DOI: https://doi.org/10.11144/Javeriana.cc21.derf

Aceptado: 05 Julio 2020

Publicado: 19 Diciembre 2020

\section{Resumen:}

El propósito de este artículo es analizar esa delgada línea que limita el cumplimiento de los principios básicos de la ética profesional del contador público que trabaja bajo la figura del revisor fiscal, conforme a lo establecido en el artículo 37 de la Ley 43 de 1990 y el artículo 211 del Código de Comercio de Colombia, en concordancia con el artículo 41 de la Ley 43 de 1990 y el Código de Ética para Profesionales de la Contabilidad emitido por la Federación Internacional de Contadores; más específicamente, en relación con el principio de independencia que está desfigurado por los efectos del tipo de contrato de trabajo por el cual está vinculado a las empresas donde presta sus servicios profesionales. La gestión correcta de esta relación laboral muestra que el contador público sigue estando facultado para cumplir con la ley para dar fe pública; o que, por el contrario, está deshabilitado por la dependencia mental que impide que su trabajo se realice con la objetividad que establecen las normas que rigen la profesión.

Códigos JEL: H20, K34, M40.

Palabras clave: Dilema de la ética, revisor fiscal, contrato laboral, subordinación, fe pública.

\section{Abstract:}

The purpose of this article is to analyze that thin line that limits compliance with the basic principles of professional ethics from the public accountant who works under the figure of the statutory auditor, in accordance with the provisions of article 37 of Law 43 of 1990 and article 211 of the Colombian Commercial Code, in accordance with article 41 of Law 43/90 and the Code of Ethics for Accounting Professionals issued by the International Federation of Accountants; more specifically, in relation to the principle of independence which is disfigured by the effects of the type of employment contract by which it is linked to the companies where it provides its professional services. The correct management of this employment relationship shows that the public accountant continues to be empowered to comply with the law to give public faith; or that; on the contrary, it is disabled by the mental dependence that prevents its work from being carried out with the objectivity established by the rules governing the profession.

JEL Codes: H20, K34, M40.

Keywords: Ethics dilemma, public accountant, employment contract, subordination, public faith.

\section{Resumo:}

O objetivo deste artigo é analisar aquela linha tênue que limita o cumprimento dos princípios básicos da ética profissional do contador público que exerce as funções de auditor, de acordo com o disposto no artigo 37 da Lei 43 de 1990 e no artigo 211 do Código de Comércio da Colômbia, em conformidade com o artigo 41 da Lei 43 de 1990 e o Código de Ética para Profissionais de Contabilidade, emitido pela Federação Internacional de Contadores; mais especificamente, no que se refere ao princípio de independência que é desfigurado pelos efeitos do tipo de contrato de trabalho que o vincula às sociedades onde presta a sua atividade profissional. A correta gestão dessa relação de trabalho mostra que o contador público continua com poderes para cumprir a lei para dar fé pública; ou que, ao contrário, esteja incapacitado por dependência mental que impede que seu trabalho seja realizado com a objetividade estabelecida pelas normas que regem a profissão.

Códigos JEL: H20, K34, M40.

Palavras-chave: Dilema ético, auditor tributário, contrato de trabalho, subordinação, fé pública.

Notas de autor 


\section{Introducción}

En sicología, un dilema ético se define como el "conflicto entre procesos morales, éticos y emocionales y las normas jurídicas.” (Víctor, en EFPA, 2009). El dilema de la ética del revisor fiscal, que actúa bajo contrato laboral, radica de igual manera, en la lucha moral, ética y emocional vs. las normas contempladas en el Código de ética para profesionales de la contabilidad de la IFAC, la Federación Internacional de Contadores Públicos, que es de aplicación universal, como también, aquellas normas que rigen a la profesión con carácter exclusivo para Colombia, entre las que se destaca la Ley 43 de 1990. Una característica que identifica a la profesión contable, y especialmente a quienes se desempeñan como revisores fiscales, es que asumen la responsabilidad de actuar en interés público. En consecuencia, la responsabilidad de un profesional de la contabilidad no consiste exclusivamente en satisfacer las necesidades de un determinado cliente o de la entidad para la que trabaja (Código de ética para profesionales de la contabilidad, IFAC). Sino que es una profesión que tiene como fin satisfacer necesidades de la sociedad, mediante la medición, evaluación, ordenamiento, análisis e interpretación de la información financiera de las empresas o los individuos y la preparación de informes sobre la correspondiente situación financiera, sobre los cuales se basan las decisiones de los empresarios, inversionistas, acreedores, demás terceros interesados y el Estado (art. 35 Ley 43 de 1990).

Sin embargo, cada día, aumenta considerablemente el número de escándalos en los cuales se ven involucrados los contadores y revisores fiscales. Situación que llevó a cuestionarnos, si el tipo de contrato laboral, coacciona la independencia mental; y se convierte, en una de las principales causas de violaciones a la moral, la ética, los principios fundamentales, y las normas que rigen a la profesión.

\section{Marco conceptual}

Para alcanzar los objetivos de este artículo es necesario recordar algunos conceptos claves con relación a la definición de contrato de trabajo, tipos de contrato de trabajo y los elementos esenciales del mismo.

Trabajo: en Colombia, el Código Sustantivo del Trabajo, en su artículo 5 define trabajo, como "toda actividad humana libre, ya sea material o intelectual, permanente o transitoria, que una persona natural ejecuta conscientemente al servicio de otra, y cualquiera que sea su finalidad, siempre que se efectúe en ejecución de un contrato de trabajo". (Código Sustantivo del Trabajo-CST-Título preliminar. Principios generales, art. 5).

Contrato de trabajo: el artículo 22 del CST, define contrato de trabajo, como "aquél por el cual una persona natural se obliga a prestar un servicio personal a otra persona, natural o jurídica, bajo la continua dependencia o subordinación de la segunda y mediante remuneración".

Elementos esenciales del contrato de trabajo: para que haya contrato de trabajo se requiere que concurran estos tres elementos esenciales: a) La actividad personal del trabajador, es decir, realizada por sí mismo; b) La continuada subordinación o dependencia del trabajador respecto del empleador, que faculta a éste para exigirle el cumplimiento de órdenes, en cualquier momento, en cuanto al modo, tiempo o cantidad de trabajo, e imponerle reglamentos, la cual debe mantenerse por todo el tiempo de duración del contrato. Todo ello sin que afecte el honor, la dignidad y los derechos mínimos del trabajador en concordancia con los tratados o convenios internacionales que sobre derechos humanos relativos a la materia obliguen al país; y c) Un salario como retribución del servicio. Una vez reunidos los tres elementos, se entiende que existe contrato de trabajo y no deja de serlo por razón del nombre que se le dé ni de otras condiciones o modalidades que se le agreguen (art. 23 CST).

Relación laboral: aquella relación contractual entre una empresa o persona llamada empleador y una persona natural llamada trabajador o empleado, relación mediante la cual el trabajador pone a disposición del empleador su capacidad física e intelectual para desarrollar una actividad determinada. 
Subordinación: término de origen latino que se refiere a la relación de dependencia entre un elemento y otro. Subordinación laboral: poder de dirección en la actividad laboral y la potestad disciplinaria que el empleador ejerce sobre sus trabajadores para mantener el orden y la disciplina en su empresa.

Tipos de contrato de trabajo: para efectos de este ensayo vamos a enfocarnos en dos tipos de contrato regulados por el Código Sustantivo de trabajo, los cuales son: el contrato a término fijo y el contrato a término indefinido. Y el conocido y generalizado contrato de prestación de servicios, regulado por el Código Civil.

Contrato a término fijo: el contrato de trabajo a término fijo debe constar siempre por escrito y su duración no puede ser superior a tres años, pero es renovable indefinidamente (art. 46 CST.

Contrato a término indefinido: el contrato de trabajo no estipulado a término fijo, o cuya duración no esté determinada por la de la obra, o la naturaleza de la labor contratada, o no se refiera a un trabajo ocasional o transitorio (art. 47 CST y art. 28 de la Ley 789 de 2002

Contrato de prestación de servicios: contrato o convención es un acto por el cual una parte se obliga para con otra a dar, hacer o no hacer alguna cosa. Cada parte puede ser de una o de muchas personas (art. 1495 Código Civil colombiano.

En todo contrato de prestación de servicios, quien presta el servicio es el contratado, y este recibe un pago o remuneración, puesto que no existen contratos de servicio gratuitos, por lo que el elemento que entraría a definir si lo que existe en la realidad es una relación laboral, es la subordinación. Son innumerables las inquietudes de la gente que está vinculada mediante la figura de contrato de servicios, sin embargo, están permanentemente subordinas al contratante. (Nieto Salazar, 2013)

\section{Independencia mental del contador público}

Empezaremos definiendo el principio de independencia, apoyados en la Ley 43 de 1990, reglamentaria de la profesión del contador público, y el Código de ética para profesionales de la contabilidad, IFAC.

En el ejercicio profesional, el contador público deberá tener y demostrar absoluta independencia mental y de criterio con respecto a cualquier interés que pudiere considerarse incompatible con los principios de integridad y objetividad, con respecto a los cuales la independencia, por las características peculiares de la profesión contable, debe considerarse esencial y concomitante. (art. 37.3 Ley 43 de 1990)

La independencia comprende: actitud mental independiente que permite expresar una conclusión sin influencias que comprometan el juicio profesional, permitiendo que una persona actúe con integridad, objetividad y escepticismo profesional. (Código de Ética para profesionales de la contabilidad, IFAC. Sección 290.6)

La Junta Central de Contadores también se manifiesta expresando una opinión al respecto de la independencia:

La independencia supone una actitud mental que permite al contador público actuar con libertad respecto a su juicio profesional, para lo cual debe encontrarse libre de cualquier predisposición que limite su imparcialidad en la consideración objetiva de los hechos, así como en la formulación de sus conclusiones. Por su parte, la objetividad implica el mantenimiento de una postura imparcial en todas las funciones del contador público, de quien se exige total independencia en sus relaciones con la entidad o persona objeto de fiscalización. (Junta Central de Contadores de Colombia, 1999)

Finalmente, en la orientación profesional del ejercicio de la revisoría fiscal, emitida por el Consejo Técnico de la Contaduría Pública, al respecto de la independencia manifiesta este organismo lo siguiente:

Independencia: en la calidad de institución designada por el máximo estamento del ente económico Asamblea, Junta General de Socios o máximo órgano de dirección-, y advirtiendo que las funciones emanan de la ley, la independencia de la Revisoría Fiscal está a salvo de presiones administrativas, por lo que su labor se puede sustentar sin ningún impedimento, en la capacidad y buen juicio profesional de sus representantes.

Por ello, el Revisor Fiscal no obedece ordenes o instrucciones de la junta directiva, la presidencia o gerencia del ente económico, ni de ningún otro estamento administrativo; por el contrario, supervisa y vigila las actuaciones de todos estos administradores y de todas las demás personas que ejercen funciones de dirección 
o administración, pudiendo incluso llamarles la atención o informar a la asamblea o junta general de socios, o a las autoridades competentes -según los casos- de cualquier actuación irregular en la gestión adelantada. Se hace notar el hecho, de que un presidente o gerente de un ente económico suscriba el contrato de vinculación del Revisor Fiscal, no implica subordinación de ningún tipo.

$\mathrm{Al}$ respecto la Superintendencia Bancaria expresó:

El Revisor Fiscal debe cumplir con las responsabilidades que le asigna la ley y su criterio debe ser personal, basado en las normas legales, en su conciencia social y en su capacidad profesional. En todo caso su gestión debe ser libre de todo conflicto de interés que le reste independencia y ajena a cualquier tipo de subordinación respecto de los administradores que son, precisamente, los sujetos pasivos de su control. (Superintendencia Bancaria, 2007)

En las anteriores definiciones, encontramos palabras en común: integridad y objetividad. Dos de los principios básicos de ética profesional del contador público. Según el diccionario de la Real Academia de la Lengua -RAE-, la integridad hace referencia a "cualidad de íntegro" dicho de una persona recta, proba, intachable. Y la objetividad, se relaciona con la "cualidad de objetivo" perteneciente o relativo al objeto en sí mismo, con independencia de la propia manera de pensar o de sentir.

Salvedades establecidas por la ley al principio de independencia:

A continuación, se analizarán dos consultas referentes a si "un contador público puede ser vinculado mediante contrato laboral para ejercer el cargo de revisoría fiscal”. El primero, resuelto por el Ministerio del Trabajo a través del concepto 08SE2019120300000005653 del 22 de febrero de 2019, el cual textualmente cita:

Las normas de derecho laboral no restringen ni prohíben la vinculación laboral de quien efectúa la revisoría fiscal. Sin embargo, la Corte Suprema de Justicia, Sala de Casación Civil, en la sentencia del 15 de noviembre de 2017 (ID: 591992 , número de proceso: 57584, número de providencia: SL19843-2017) consideró que: Es necesario decir, al respecto, que de la lectura de los artículos 203 a 217 del Código de Comercio y el parágrafo $2^{\circ}$ del artículo 13 de la Ley 43 de 1990, que obligan a las empresas a contar de manera obligatoria como un revisor fiscal, es dable entender que los mismos no fungen como asesores económicos de una empresa, como es el caso de los contadores públicos, sino que se presentan como garantes del Estado y particularmente de los socios o accionistas o asociados de una persona jurídica, en la inspección y vigilancia de la actividad societaria para el cumplimiento de las normas legales y estatutarias en los manejos contables.

Así, el artículo 213 del Código de Comercio los faculta, en caso de duda, para inspeccionar en cualquier momento los documentos contables de la empresa, a fin de dar fe pública en la autorización de los balances financieros, atendiendo a responsabilidades de tipo penal como lo consagra el artículo 212 del mismo estatuto, con ocasión de la aprobación de inexactitudes graves o rendición de cuentas impropia ante la asamblea o junta de socios, lo cual explica su carácter independiente de la administración de la empresa y el origen no subordinado de la prestación de sus servicios, reforzado con el hecho de que el parágrafo del artículo 10 de la Ley 43 de 1990, los equipara a la categoría de funcionarios públicos para efectos de las sanciones penales por los delitos que cometieran en el ejercicio de las actividades propias de su función.

En aras de sustentar la postura anterior, el Ministerio de trabajo trajo a colación la Sentencia bajo radicado 57854 de 2017 de la Corte Suprema de Justicia, a través de la cual se resuelve la responsabilidad del revisor fiscal por los balances e informes que presente. De entre lo que dice la Sentencia se puede destacar:

El artículo 213 del Código de Comercio los faculta, en caso de duda, para inspeccionar en cualquier momento los documentos contables de la empresa, a fin de dar fe pública en la autorización de los balances financieros, atendiendo a responsabilidades de tipo penal como lo consagra el artículo 212 del mismo estatuto, con ocasión de la aprobación de inexactitudes graves o rendición de cuentas impropia ante la asamblea o junta de socios, lo cual explica su carácter independiente de la administración de la empresa y el origen no subordinado de la prestación de sus servicios, reforzado con el hecho de que el parágrafo del artículo 10 de la Ley 43 de 1990, los equipara a la categoría de funcionarios públicos para efectos de las sanciones penales por los delitos que cometieran en el ejercicio de las actividades propias de su función.

En consecuencia, el tipo de vinculación dependerá de lo que establezcan los estatutos de la correspondiente persona jurídica que requiera de la revisoría fiscal. Ejercicio que estará subordinado al máximo órgano de gobierno del correspondiente ente jurídico. 
De igual forma, el Consejo Técnico de la Contaduría Pública en consulta No. 023/2007, se manifiesta al respecto, dando respuesta a la pregunta relacionada con la forma de contratación del revisor fiscal.

Consulta (Textual): ¿Un revisor fiscal puede ser vinculado por contrato laboral, entendiendo que este tipo de relación consagra el elemento de subordinación o dependencia?

Respuesta: Respecto del interrogante planteado en la pregunta, nos permitimos sintetizar las consideraciones puntuales, sobre el tema de la contratación y subordinación del revisor fiscal en una entidad, sobre las cuales se ha pronunciado el Consejo Técnico, atendiendo las disposiciones legales vigentes sobre el tema.

1. En aquellos casos en que el revisor fiscal sea una persona natural, su vinculación puede hacerse mediante contrato de trabajo, o mediante contrato de prestación de servicios profesionales, en el entendido de que el revisor fiscal es un órgano de control independiente de la administración del ente económico y tiene completa autonomía para el desempeño de sus funciones siempre en cumplimiento de las disposiciones legales que le sean aplicables.

2. Ratificando lo anterior nos remitimos al Código de Comercio, que en su artículo 210, inciso $2^{\circ}$, establece: "El revisor fiscal solamente estará bajo la dependencia de la asamblea o de la junta de socios." Como bien se observa, el revisor fiscal en una sociedad responde solamente ante la asamblea o junta de socios, quienes lo eligen y fijan su remuneración; por tanto, cuando el revisor fiscal se vincula mediante contrato laboral, contrato del cual se predica como elemento esencial la subordinación continuada, ésta se entiende únicamente frente a los máximos directivos de la organización y no ante la administración.

En consideración a que el revisor fiscal goza de completa autonomía para la realización y cumplimiento de sus funciones lo verdaderamente importante en su desempeño es la idoneidad profesional, que le permita adelantar su trabajo de forma independiente y objetiva, tal como lo establece la Ley 43 de 1990 en sus artículos $6,8,10,35,36,37$ y 70 .

En razón de lo anterior, se ratifica que para el ejercicio de la revisoría fiscal la forma de vinculación del Revisor Fiscal no limita el alcance de su trabajo, ya que no obstante presentarse el elemento de subordinación, ésta se entiende sólo ante la asamblea o junta de socios de la entidad.

Es fácil observar, que tanto el Ministerio de Trabajo, como el Consejo Técnico de la Contaduría Pública coinciden en el hecho de que el revisor fiscal no pierde su independencia al estar vinculado laboralmente mediante un contrato de trabajo. Por lo tanto, sigue facultado para dar fe pública sobre la razonabilidad de los estados financieros, validar informes con destino a las entidades gubernamentales y juzgar sobre los actos de los administradores.

Siguiendo el concepto del Ministerio de Trabajo, se concluye que en la ley laboral no existe restricción ni prohibición alguna para la contratación del revisor fiscal mediante un contrato de trabajo; razón por la cual puede efectuarse su contratación por el modelo de contrato de trabajo que el empleador considere pertinente, o por la figura civil del contrato de prestación de servicios.

Sin embargo, la norma, al igual que estas instituciones que avalan la independencia mental de estos profesionales, por encima de la subordinación laboral, no pueden controlar que "Las actividades de este funcionario garanticen la subordinación de la actividad empresarial a la normatividad jurídica" (Ruiz, 2001).

Al tenor de lo anterior, el artículo primero de la Ley 43 de 1990, en su segundo párrafo, taxativamente señala una salvedad a la inhabilidad que acarrea la dependencia laboral del profesional contable para dar fe pública, señalando que "no aplica a los revisores fiscales ni a los contadores públicos que presten sus servicios a sociedades que no están obligadas, por ley o por estatutos, a tener revisor fiscal" (art. 1 Ley 43 de 1990).

En este punto se desprenden dos divisiones importantes relacionadas con las empresas que están o no obligadas por ley o por estatutos a tener revisor fiscal, y determinar de esta manera el alcance de la inhabilidad señalada por la Ley 43 de 1990. 


\section{Empresas obligadas por ley o por estatutos a tener Revisor Fiscal}

La Ley 43 de 1990 y el Código de Comercio colombiano establecen de manera clara a quienes sí aplica la inhabilidad de la dependencia laboral en el ejercicio profesional del contador público y revisor fiscal.

Artículo 203. Deberán tener revisor fiscal:

- Las sociedades por acciones.

- Las sucursales de compañías extranjeras.

- Las sociedades en las que, por ley o por estatutos, la administración no corresponda a todos los socios, cuando así lo disponga cualquier número de socios excluidos de la administración que representen no menos del veinte por ciento del capital (Código de Comercio Colombiano).

Será obligatorio tener revisor fiscal en todas las sociedades comerciales, de cualquier naturaleza, cuyos activos brutos al 31 de diciembre del año inmediatamente anterior sean o excedan el equivalente de cinco mil salarios mínimos y/o cuyos ingresos brutos durante el año inmediatamente anterior sean o excedan al equivalente a tres mil salarios mínimos. (Artículo 13, Par. 2º Ley 43 de 1990)

Este grupo de empresas son las denominadas sociedades de capital, caracterizadas porque se constituye el capital sin importar quiénes son los socios, y de allí que su responsabilidad es limitada, pues los socios responden por sus obligaciones hasta el monto de sus aportes, es decir, el elemento que prevalece en este tipo de sociedades es el Intuitu Rei, lo que la constituye en una estructura de carácter abierto.

Este grupo de sociedades dividen su capital en tres categorías: autorizado, suscrito y pagado. De esta manera es fácil determinar la capacidad de endeudamiento. Las sociedades de capital delegan sus decisiones a un órgano consultivo que debe aparecer en el contrato social y que asesoran al gerente en el giro de los negocios. Esas decisiones se toman por voto, y cada socio tendrá un determinado número de votos, dependiendo de las acciones que éste posea (Peña Nossa, 2014).

Los revisores fiscales vinculados a estas empresas, mediante un contrato laboral, se encuentran inhabilitados para dar fe pública sobre actos que interesen a su empleador. "Si entendemos la fe pública como una opinión independiente cuyo pilar fundamental es la independencia mental del contador, nos encontramos ante una gran contradicción”. (Ruíz, 2001, p. 358).

Al existir la relación contractual, sin importar si se ejerce como contador o revisor fiscal, el contador público como agente fiscalizador responde a los intereses del objeto fiscalizado y, al mismo tiempo y en la misma posición, a los intereses del agente fiscali8zador, esto explica la gran contradicción. (Ruíz, 2001, p. 109)

La subordinación existe. Las funciones y obligaciones de estos profesionales se rigen por un contrato laboral. Por consiguiente, el contador público y el revisor fiscal que trabajan bajo estas condiciones, adolecen de independencia mental y de dar fe pública. La ley que establece los lineamientos, regula las actividades, e impone sanciones; es la misma que permite concesiones, creando espacios que son aprovechados para cometer delitos.

Se están violando los principios básicos de la ética profesional. Principios que son indisolubles. Sin ética e independencia mental, el contador público es como un barco llevado por las olas de las oportunidades de infringir la ley y obtener beneficios particulares. Desafortunadamente, los entes reguladores del cumplimiento de las normas señaladas no cuentan con los mecanismos apropiados de control que garanticen su correcta aplicación; confiando el cumplimiento de esta responsabilidad en los hombros de la ética y la moral del mismo gremio contable objeto de regulación. 


\section{Empresas no obligadas por ley o por estatutos a tener Revisor Fiscal}

No están obligadas a tener revisor fiscal las empresas que no están contempladas en el artículo 203 del Código de Comercio Colombiano. Asimismo, las empresas que no están contempladas en el artículo 13, parágrafo $2^{\circ}$ de la Ley 43 de 1990, porque no cumplen con los montos de activos e ingresos brutos señalados en el mismo.

Estas empresas son las conocidas como sociedades de personas. Son aquellas que tienen interés en las calidades personales de cada uno de los socios y no en el capital que aportan. Por consiguiente, la responsabilidad de cada uno de los socios en este tipo de sociedades es solidaria, y no tiene en cuenta el aporte dado por los socios para la constitución de la sociedad. La tenencia de la figura de revisor fiscal es optativa para este grupo de empresas, sin embargo, en consideración a la ayuda en el control y vigilancia que representa este profesional; es viable que existan empresas que decidan contratarlo, o en su defecto contratar una auditoría externa.

Se entiende entonces, que todo contador y/o revisor fiscal, que preste sus servicios profesionales en este grupo de empresas, puede firmar cualquier tipo de contrato que se deriva en una relación de dependencia laboral, y aun así continuar facultado para dar fe pública. Corresponde al contador público la incorporación de la información en el proceso contable para producir los estados financieros, ciñéndose a las normas y estándares internacionales; las cuales debe cumplir a pesar de que su labor esté subordinada a la administración de la compañía. Esta última es responsable por la preparación y presentación razonable de los estados financieros, de acuerdo con Normas Internacionales de Información Financiera; responsabilidad que incluye: diseñar, implementar y mantener el control interno relevante para la preparación y presentación razonable de estados financieros, que estén libres de representaciones erróneas de importancia relativa, debido ya sea a fraude o error; seleccionar y aplicar políticas contables apropiadas; y efectuar estimaciones contables que sean razonables en las circunstancias.

\section{Zapatero a tus zapatos}

Es obligatorio que el contador público, y especialmente, el revisor fiscal entiendan, que en sus manos está la decisión de coadministrar con las consecuencias de "escándalos financieros en las que se ven envueltos a causa de su permisividad, donde las relaciones entre clientes y profesional se ven afectadas por la subjetividad y el encubrimiento de malas prácticas" (López Carvajal, 2013). O, por el contrario, subordinar su labor a las normas y a los principios éticos de su profesión.

Esto sólo es posible si comprenden la magnitud de la figura de la revisoría fiscal como "institución de origen legal, de carácter profesional a la cual le corresponde por ministerio de la ley, bajo la responsabilidad de un profesional contable, con sujeción a normas que le son propias vigilar integralmente los entes económicos, dando fe pública de sus actuaciones" (CTCP, junio, 2008).

El revisor fiscal es la cabeza de esa institución. Aquí se encuentra la esencia. Esto es lo que debe aprehender este profesional, de lo contrario, continuará cometiendo errores que lo llevarán a la pérdida de su independencia, al interponer sus intereses personales a los de la comunidad.

\section{La realidad}

Curiosamente las empresas obligadas por ley o por estatutos a tener revisor fiscal, son las que más se destacan en la ocurrencia de irregularidades por parte de estos profesionales. Evidencia de esto son los siguientes casos: Caso Odebrecht. Involucrados: el contador Héctor William Santos Jiménez y los revisores fiscales Camilo Reyes y Diego Armando Lara, de la firma Price Waterhouse 12 Cooper. Además de las investigaciones a las 
firmas auditoras como KPMG y Delloitte Touche Tohmatsu Limited (Delloitte), quienes estaban a cargo de la auditoría de la construcción de la Autopista o Ruta del Sol, las cuales, al parecer, omitieron información de los asientos contables donde se reflejaba el pago de los sobornos.

Caso SaludCoop. Involucrados: Algunas personas implicadas en este caso de corrupción contra la salud de los colombianos son: Carlos Palacino presidente del grupo Saludcoop, Vicepresidenta administrativa María Carolina Lamus, Luis Albeiro Medina, Jaime Chávez, Audigroup SAS Empresa de auditoría y Procesos y Transacciones P\&T Ltda. Empresa encarga de la revisoría fiscal.

Caso InterBolsa. Involucrados: Grant Thornton Fast \& ABS Auditores Ltda., compañía encargada de la revisoría fiscal; Ulfany Castillo López, revisora fiscal encargada para InterBolsa y Carlos Alberto Posada González, contador y empleado de InterBolsa.

Caso Reficar. Involucrados: Los resultados de la auditoría realizada en el primer semestre de 2017 a la Refinería de Cartagena S.A., desarrollada por la Contraloría General de la República, evidencia en comunicado de prensa No. 126 del 25 de agosto: las pérdidas en el 2016 de $\$ 2.960$ millones se tomaron del estado de resultado integrales, suscritos por el representante legal de la empresa, el contador y la firma Ernts \& Young como revisor fiscal.

Caso Sayco y Acinpro. Entre los involucrados más nombrados están: Juan Carlos Monroy (director de la oficina de derechos de autor) y Jairo Enrique Ruge (gerente de Sayco), así como el contador José Miguel Soler Díaz y el revisor fiscal Jorge Ernesto Sánchez Pérez.

En los casos revisados anteriormente se evidencia una participación directa de los contadores públicos y revisores fiscales dentro de actos ilícitos que han terminado en investigaciones por corrupción y fraude. Por otro lado, es claro que las sanciones impuestas por el tribunal disciplinario de la Junta Central de Contadores son débiles y no son coherentes con la gravedad de las faltas cometidas por los contadores, revisores fiscales y empresas de auditoría y revisoría fiscal. En general, para los casos expuestos, las sanciones impuestas por Tribunal disciplinario de la Junta Central de Contadores son débiles porque han consistido en una suspensión temporal por no más de un año (caso Saludcoop y Sayco y Acinpro) y la más contundente fue la cancelación de la inscripción del registro profesional a Grant Thornton Fast \& ABS Auditores Ltda., en el caso de Interbolsa.

Además no son coherentes con la gravedad de las faltas porque los daños patrimoniales fueron significativos y los aspectos sociales fueron vulnerados como: mala prestación de servicios de salud (Saludcoop), el atrasos en la industrialización del país dada en las demoras en los contratos con entidades estatales, desvío de recursos económicos del estado (Reficar) y la especulación financiera (Interbolsa) dan la sensación de inconformidad del actuar profesional del contador público.

Como se observa, las conductas antiéticas son múltiples y de alta gravedad, en contraste con las sanciones, las cuales, son temporales y no garantizan la no reincidencia por parte de los sancionados en estas malas prácticas profesionales (Martínez, \& Peñaloza, 2018).

\section{Oportunidad, necesidad y ética}

\section{Caso uno}

En medio de una clase, el profesor plantea para debate, un caso en donde se indica que un funcionario de la oficina de planeación del gobierno nacional decide informar a sus amigos que antes de dos años se construirá una zona franca en un área rural, donde es posible comprar tierras por una mínima fracción del valor que tendrán una vez que sea anunciado públicamente el proyecto. Al plantear la pregunta de si el estudiante realizaría la compra de tierras sin informar al quien hasta ese momento era el dueño, sobre el proyecto futuro que generaría la gran valorización, fue posible observar que la toma de decisiones fue siempre el mismo "Si" 
en el $100 \%$ de los casos. Esta unanimidad en la respuesta lleva a una miríada de consideraciones sobre las implicaciones de esa forma estándar de imponer el criterio financiero sobre la ética y la moral.

Esta situación se ha vuelto tan común que ya es coloquial la expresión: "la ética es tan sólida como fuerte es el hambre", y esto, considerada la inconmensurable responsabilidad que conlleva el dar fe pública, es una situación que merece considerarse con sumo cuidado.

\section{Caso dos}

En un caluroso día, se encuentran disputando la final de un campeonato de futbol, dos reconocidas empresas, a las que llamaremos equipo A y equipo B. El equipo A lleva la delantera, a causa de tres jugadores estrellas, conformados por el revisor fiscal y dos miembros de la junta directiva. Finalizado el segundo tiempo, la empresa $\mathrm{A}$ es la ganadora de la copa inter-empresas. La alegría y camaradería los llevan a celebrar con unas cervezas bien frías. Pasado un tiempo, y ya agotado el tema del festejo por la victoria; la conversación de estos tres funcionarios, se desvía a un tema netamente financiero y tributario de la empresa que necesitan definir, y al que le llaman "el asunto". El revisor fiscal los tranquiliza diciéndoles que todo está arreglado. Que no tienen por qué preocuparse porque él jamás "va a patear la lonchera”. Ante esta frase los tres ríen a carcajadas, y los miembros de la junta directiva, felicitan con una palmada en el hombro del revisor fiscal.

Infortunadamente para la credibilidad de nuestra profesión, la anterior, es una imagen que se repite al interior de muchas empresas. La ética es reemplazada por oportunidad y necesidad económica. Los contadores públicos y revisores fiscales por conveniencia personal no aplican oportunamente los principios y salvaguardas establecidos en el código de ética para profesionales de la contabilidad. La independencia mental es reemplazada, por una dependencia consciente hacia los dueños de la compañía que lo remuneran (Blanco Simbaqueva, 2017).

\section{Conclusión}

Este artículo presenta varios casos donde la conducta ética de los revisores fiscales queda cuestionada a partir de actuaciones permisivas en su labor de vigilancia y control; y, que han comprometido seriamente la confianza pública, patrimonio invaluable de la profesión. Desde luego que es muy fácil llegar a verse comprometido en un acto de corrupción, pues muchas veces al revisor fiscal se le plantean situaciones difíciles en donde está de por medio su estabilidad laboral, más grave aún, su sustento. Solo una definitiva convicción hacia la rectitud generaría en el revisor fiscal una actitud encaminada hacia la disminución de la corrupción. (López, 2011).

Los contratos que firman los contadores públicos, sin importar el nombre que reciban, tienen latente la subordinación laboral que conllevan a una inequívoca dependencia mental. Esto, sumado a la ausencia de ética personal y profesional, y a la ineficacia de los organismos de control y vigilancia disciplinaria de la profesión del contador público, ocasiona la perpetuación de los ya conocidos escándalos financieros en los que participan estos profesionales. Estas acciones reafirman la necesidad de que existan dos tipos de licencias para los profesionales contables, una para el contador que trabaja subordinado y que se ve impedido para dar fe pública por su misma dependencia económica, y otra para el verdadero "contador público" que al no depender económicamente, no ve comprometidas su moral y su capacidad de decidir respecto a una situación.

\section{Referencias}

Blanco Simbaqueva, A. (2017). Causas que influyen en la limitación de la Independencia mental en el ejercicio de la Revisoria Fiscal para la empresa privada en Colombia. Bogotá: Universidad Militar Nueva Granada. https://repo sitory.unimilitar.edu.co/bitstream/handle/10654/16486/BlancoSimbaquevaAnderson2017.pdf?sequence=2. 
Consejo Técnico de Contaduría Pública. (2008). Orientación Profesional, Ejercicio Profesional de la Revisoría Fiscal, 21 de junio de 2008. CTCP.

EFPA (2009). Comité Permanente de Ética de la Federación de Asociaciones de Psicólogos -EFPA- de Europa.

Franco Ruiz, R. (2001). Reflexiones Contables. Universidad Libre de Colombia Seccional Bogotá. Recuperado de http ://www.unilibre.edu.co/bogota/pdfs/2017/reflexiones-contables.pdf

López Carvajal, Ó. (2013). La revisoría fiscal y la corrupción en Colombia. Contaduría Universidad De Antioquia, (58-59), 185-195. https://revistas.udea.edu.co/index.php/cont/article/view/14635

Martínez Fernández, J., \& Peñaloza Suarez, M. (2018). Análisis de cinco casos antiéticos en el actuar profesional del contador público y sus consecuencias disciplinarias. Recuperado de https://ciencia.lasalle.edu.co/contaduria_pub lica/675

Nieto Salazar, D. A. (2013). La subordinación en los diferentes contratos laborales. Universidad de Manizales. https://n anopdf.com/download/la-subordinacion-en-los-diferentes-contratos-laborales-jun-19_pdf

Peña Nossa, L. (2014). De las sociedades comerciales, $7^{\mathrm{a}} \mathrm{ed}$. Bogotá: ECOE Ediciones.

Superintendencia Bancaria de Colombia (2007). Circular 052 de 2007.

\section{Notas}

* Artículo de reflexión.

\section{Licencia Creative Commons CC BY 4.0}

Para citar este artículo: Olaya, M., \& Ortiz, T. O. (2020). El dilema de la ética del revisor fiscal que actúa bajo contrato laboral: el caso colombiano. Cuadernos de Contabilidad, 21. https://doi.org/10.11144/Javer iana.cc21.derf 